\title{
A LIMITAÇÃO DA REMUNERAÇÃO DO ADMINISTRADOR JUDICIAL DA FALÊNCIA E RECUPERAÇÃO JUDICIAL NA PERSPECTIVA DA PRESERVAÇÃO DA EMPRESA
}

\section{THE LIMITATION OF THE PAYMENT OF THE JUDICIAL ADMINISTRATOR OF BANKRUPTCY AND JUDICIAL RECOVERY WITH A VIEW TO PRESERVING THE COMPANY}

MANOEL DE QUEIROZ PEREIRA CALÇAS

Presidente do Tribunal de Justiça de São Paulo. Desembargador da $1^{\text {a }}$ Câmara Reservada de Direito Empresarial. Doutor e Mestre em Direito pela Pontifícia Universidade Católica de São Paulo (PUC/SP). Professor de Direito Comercial da Faculdade de Direito do Largo de São Francisco (USP), da Faculdade de Direito da Pontifícia Universidade Católica de São Paulo (PUCSP), do Centro Universitário de Bauru (CEUB - ITE) e da Universidade Nove de Julho (UNINOVE). E-mail: manoelpereira@uol.com.br

\section{RUTH MARIA JUNQUEIRA DE ANDRADE PEREIRA E SILVA}

Doutora e Mestre em Direito pela Pontifícia Universidade Católica de São Paulo (PUC/SP). Visiting Academic na Université Panthéon-Assas - Paris II. Professora de Direito Comercial da Graduação e da Pós-Graduação em Direito do Centro Universitário de Bauru. Advogada. E-mail: ruthpereira@uol.com.br

\section{THIAGO MUNARO GARCIA}

Doutorando e Mestre em Direito pelo Centro Universitário de Bauru. Professor dos cursos de graduação e pós-graduação Lato Sensu do Centro Universitário de Bauru. Advogado. E-mail: thiagogarcia@mandaliti.com.br 


\section{RESUMO}

Objetivo: O objetivo deste artigo é analisar a propositura da identificação de critérios objetivos de fixação da remuneração judicial; traçar uma evolução histórica do conceito de empresa, relacionando a distinção entre o papel do antigo síndico e a figura do administrador judicial; pesquisar os parâmetros da legislação brasileira, acompanhado da posterior referência ao direito estrangeiro e analisar casos brasileiros e a inconstância dos valores fixados a título de remuneração.

Metodologia: A metodologia eleita seguiu uma abordagem indutiva por meio de um procedimento histórico, monográfico e comparativo, por meio do qual buscou-se analisar a legislação adotada pela Colômbia, Itália, França e Estados Unidos da América para refletir-se sobre a necessidade de adotar parâmetros mais específicos no que concerne à justa e adequada fixação da remuneração do administrador judicial na recuperação judicial.

Resultados: Considerando o levantamento dos dados em torno da problemática sugerida neste artigo, a fixação da remuneração do administrador deve seguir critérios objetivos de modo a viabilizar a função social da empresa e o soerguimento desta, sem que ocorra o enriquecimento sem causa do auxiliar da Justiça.

Contribuições: A principal contribuição deste estudo reside no apontamento de soluções que reflitam diretamente na manutenção dos empregos dos trabalhadores, protegendo-se os interesses dos credores, de modo a preservar a empresa e sua função social, além de promover o estímulo à atividade econômica.

Palavras-chave: Recuperação judicial; falência; administrador; remuneração; razoabilidade.

\section{ABSTRACT}

Objective: To analyze the proposal for the identification of an objective criteria for setting judicial compensation; to trace a historical evolution of the company concept, relating the distinction between the role of the former liquidator and the figure of the judicial administrator; to research the parameters of Brazilian law accompanied by the subsequent reference to foreign law; and to analyze Brazilian cases and the inconsistency of the values set as compensation.

Methodology: The chosen methodology followed an inductive approach by way of a historical, monographic and comparative procedure searching to analyze the legislation adopted by Colombia, Italy, France and the United States of America to reflect on the need to adopt parameters more specific regarding the fair and 
adequate setting of the compensation of the judicial administrator in the judicial recovery.

Results: Considering the data survey on the issues suggested in this paper, the setting of the administrator's compensation must follow objective criteria in order to make the company's social function and uplift without the unjust enrichment of the Justice assistant.

Contributions: The main contribution of this study lies in pointing out solutions that directly reflect the maintenance of workers' jobs and protect the interests of creditors in order to preserve the company and its social function, in addition to promoting the stimulus to economic activity.

Keywords: Judicial reorganization; bankruptcy; administrator; compensation; reasonability.

\section{INTRODUÇÃO}

Aproximando-se de completar quinze anos de vigência, a Lei n. 11.101/05 Lei de Recuperação de Empresas e Falência - que instituiu a Recuperação Judicial e Extrajudicial de Empresa e conferiu novo regramento à Falência possui dispositivos que ainda são objeto de constantes debates, controvérsias e exegeses.

A atual legislação foi aprovada já sob a égide do Código Civil de 2002, adotando a teoria italiana inspirada no Codice Civille de 1942. Introduziu no sistema legislativo brasileiro o conceito de empresa em substituição à teoria dos atos de comércio inspiradora do Código Comercial de 1850.

Com a concepção da empresa como um fenômeno poliédrico que carrega em si diversos perfis, como proposto por Asquini (1996, p.109-126), o direito brasileiro passa a valorizar a preservação da atividade empresarial, sob a ótica do princípio da função social da empresa.

A Constituição Federal de 1988 preconiza como fundamento da República a valorização do trabalho e da livre iniciativa (art. $1^{\circ}$, inciso IV) e, mais à frente, quando trata da ordem econômica, novamente salienta a propriedade privada, a função 
social da propriedade que implica a função social dos meios de produção, a liberdade de concorrência, a proteção à livre iniciativa e a busca do pleno emprego (art. 170).

Nesse contexto, cabe aos operadores do processo de recuperação judicial da empresa em crise a observância da finalidade social atrelada aos objetivos da lei, de modo que seja bem compreendida a função de cada protagonista que atua no palco judicial em que tramitem os processos de recuperação judicial ou de falência.

Entre as figuras emblemáticas da recuperação judicial e da falência, a Lei $n$. 11.101/05 modificou a disciplina da antiga função do síndico da massa falida e do comissário da concordata, para dispor a respeito da atuação do administrador judicial como auxiliar do juízo tanto na recuperação quanto na falência.

A busca na lei para as respostas às dificuldades interpretativas é uma das formas à disposição do intérprete, devendo ser levado em consideração que a legislação falimentar e recuperação judicial brasileira foi aprovada em momento de profunda transformação política e econômica do país.

Ademais, em sua vigência, o país vivenciou crises econômico-financeiras, episódios emblemáticos de apuração de intensas e graves práticas de corrupção na área político-empresarial e alto índice de desemprego, inadimplência tributária com os fiscos municipal, estadual e federal, que exigiram do Poder Judiciário uma interpretação criativa e sistemática da Lei n. 11.101/05, sob a luz dos princípios constitucionais e econômicos que informam os institutos da recuperação e falência.

É notório que a crise econômica e a corrupção sistêmica que atingiu nosso país afetou econômica e financeiramente as empresas brasileiras, o que é evidenciado pelo preocupante aumento dos pedidos de recuperação judicial e falências apresentados ao judiciário. ${ }^{1}$

Diante dos valores dos passivos envolvidos nos processos de recuperação judicial um dos temas que ensejou controvérsia foi a fixação do valor e a forma de pagamento da remuneração do administrador judicial. A lei em vigor dispõe apenas

\footnotetext{
${ }^{1}$ A Sete Brasil formulou pedido de recuperação judicial declarando débito de $R \$ 19,3$ bilhões. A empresa é a responsável pelas sondas do pré-sal. Acima dela a Oi Telecomunicações também processou sua recuperação judicial para reconstruir a dívida de $\mathrm{R} \$ 65$ bilhões. Também gigante do mundo das empreiteiras, a UTC pediu recuperação judicial com débito de $\mathrm{R} \$ 3,4$ bilhões.
} 
do limitador, qual seja, a alíquota máxima de $5 \%$ sobre o valor devido aos credores submetidos à recuperação judicial ou do valor da venda dos bens arrecadados na falência (art. 24, § $1^{\circ}$ ).

O Tribunal de Justiça do Estado de São Paulo saiu à frente dos demais na árdua missão de interpretar a Lei n. 11.101/05. Foi pioneiro em criar um órgão especial de segundo grau para o julgamento dos recursos e incidentes envolvendo os processos regulamentados pela lei: Câmara Reservada à Falência e Recuperação Judicial. ${ }^{2}$

A análise da jurisprudência da Câmara especializada demonstra que é possível impor limites mais objetivos à remuneração do administrador judicial a fim de atender aos objetivos que permeiam a legislação recuperacional, aplicando-se os princípios constitucionais que regem a atividade econômica e financeira de nosso País.

Além da jurisprudência especializada, também nos utilizaremos da legislação adotada pela Colômbia, Itália, França e Estados Unidos para refletirmos sobre a necessidade de adotar parâmetros mais específicos no que concerne à justa e adequada fixação da remuneração do administrador judicial na recuperação judicial.

\section{ELEMENTOS HISTÓRICOS À RECUPERAÇÃO JUDICIAL E FALÊNCIA}

Da concordata cuidou o art. 132 do Decreto 738 de 1850 no Brasil, que dispunha acerca da possibilidade de se evitar seja ultimada a última fase do procedimento falimentar consistente na arrecadação e expropriação dos bens do falido.

Consoante dispõe referido dispositivo legal, a falência é o processo judicial coletivo de execução forçada, por meio do qual os credores obterão o decreto de

\footnotetext{
2 Em 2005, foi instalada a pioneira Câmara Reservada à Falência e Recuperação Judicial, que teve o presidente entre seus primeiros componentes, bem como as duas primeiras Varas de Falências e Recuperações Judiciais.
} 
falência e será instaurado o concurso de credores por meio do qual cada qual receberá sua cota sobre os bens do devedor mediante a ordem legalmente estipulada.

O Código Comercial Brasileiro autorizava a concessão de concordata em caráter preventivo da falência ou caráter suspensivo, como disposto no Decreto 738 de 1850:

\begin{abstract}
Art. 840. Para ser válida a concordata suspensiva da falência, exige-se que seja concedida por um número tal de credores que represente pelo menos a maioria destes em número, e dois terços no valor de todos os créditos, sujeitos aos efeitos da concordata. Tal quórum foi reduzido no Dec. 3.065, de 1882, que passou a exigir a aprovação da maioria dos credores para concessão da concordata suspensiva.
\end{abstract}

Passando ao largo de diversas outras normas legais que regularam a insolvência dos comerciantes no Brasil, cumpre referir ao Decreto-lei n. 7.661/1945, que regulava a falência e a concordata preventiva e suspensiva. Na falência, a administração da massa falida era exercida por um síndico, sob a imediata direção e supervisão do juiz. O síndico era escolhido entre os maiores credores do falido, devendo recair a indicação entre pessoas de reconhecida idoneidade moral e financeira (arts. 59 e 60). $O$ art. 67 regulava o arbitramento de sua remuneração, devendo o juiz levar em conta a sua diligência, trabalho, responsabilidade da função e importância da massa, com base no produto dos bens ou valores vendidos ou liquidados, estipulando-se os honorários de acordo com uma tabela proporcional, gradual e cumulativa que variava de $6 \%$ a $2 \%$. Na concordata o comissário era o auxiliar do juízo e sua remuneração deveria ser arbitrada pelo juiz, considerando os mesmos critérios aplicados ao síndico, incidindo sobre o valor pago aos credores quirografários, limitada à terça parte das percentagens previstas na falência (art. 170).

A antiga concordata e falência estavam focadas no modelo de pessoa jurídica do século passado e consideravam mercantis os atos praticados pelo comerciante, em rigor a pessoa física que compunha a sociedade comercial e que exercia aquela atividade em caráter profissional. 
A contemporaneidade doutrinária e legislativa, destarte, trouxe a pessoa jurídica e a empresa para o aspecto mais aproximativo com a sociedade empresária (sistema subjetivo moderno), realçando a importância da atividade econômica organizada para o desenvolvimento social.

O direito empresarial passa a tutelar não o comerciante especificamente, mas o crédito, a circulação de bens e serviços e o mercado.

Riqueza, emprego, arrecadação de tributos, disponibilidade de serviços e bens, são as riquezas produzidas pelo exercício da atividade empresarial e que dá importância à pessoa jurídica em si, distintamente da pessoa do sócio, até porque as pessoas jurídicas são atemporais, ao passo que a vivência humana é marcada pela finitude.

Logo, a modernidade exigia um modelo de concordata e falência atualizado e que fizesse frente à importância e consequência que a quebra da empresa poderia causar na sociedade e nas pessoas diretamente envolvidas.

Além de tudo, a Constituição Federal promulgada em outubro de 1988 dispôs de forma marcante, no artigo 170, o relevo da atividade econômica e livre iniciativa, ao lado da função social da propriedade e da busca pelo pleno emprego.

Nesse contexto, em 2005, foi aprovada a Lei n. 11.101 que disciplina o regime da recuperação judicial e falências, com o escopo de, em primeiro momento, preservar a empresa recuperável e, em segundo plano, saldar as dívidas por meio da expropriação coletiva forçada, que exigiu dos operadores do direito a devida atualização operacional, segundo Sidnei Beneti, quando compunha a Câmara Especial de Falências e Recuperações de Empresas do Tribunal de Justiça de São Paulo:

A Lei n. 11.101, que 'regula a recuperação judicial, extrajudicial e a falência do empresário e da sociedade empresária', impulsiona à modernidade e exige a inovação judiciária, sem as quais não poderá produzir o desejado efeito de melhoria nas relações econômico-sociais que envolvem os momentos de crise da atividade empresarial (BEZERRA FILHO, 2006, p.10). 
O rompimento do paradigma ideológico possibilitou que, aproximando-se de quinze anos de sua vigência, a Lei de Recuperação de Empresas e Falência fosse responsável pelo soerguimento de empresas social e economicamente viáveis, bem como à extirpação dos modelos ultrapassados como forma de preservação das regras de mercado.

A Lei n. 11.101/05 aboliu a antiga concordata e redesenhou o modelo da falência, para tanto dispondo de regras claras de transparência e, tanto quanto possível, a apuração imparcial das condições da empresa. O capítulo pertinente aos crimes falimentares também foi substancialmente modificado com o objetivo de atualizar as figuras típicas de acordo com a nova tecnologia da escrituração contábil e práticas de governança corporativa.

Diante do diploma vigente, a figura do Administrador Judicial ganha relevo como auxiliar judicial com atuação de grande relevância, envolto em responsabilidades de alto calibre, cuja análise se passa a debruçar em seguida.

\section{A ANTIGA FIGURA DO SÍNDICO E O ATUAL ADMINISTRADOR JUDICIAL}

O Código Civil Brasileiro de 2002 revogou a primeira parte do antigo Código Comercial Brasileiro, adotando a teoria da empresa proveniente do direito italiano, em substituição à teoria dos atos de comércio de origem francesa.

A reforma trouxe para o arcabouço jurídico a importância que a empresa desempenha no novo quadrante da economia como vetor de desenvolvimento econômico e social.

A despeito da reforma do Código Comercial, não havia, ainda, a modificação do regime de insolvência dos comerciantes e das sociedades comerciais, de modo a adequá-lo ao novo regime do direito de empresa e sua repercussão interdisciplinar, notadamente em face das sociedades empresárias e aos grupos empresariais. 
A teoria da empresa trouxe a lume o envolvimento da atividade empresarial com a sociedade, com pessoas que não apenas aquelas diretamente ligadas à iniciativa privada, especialmente sob a ótica da doutrina asquiniana da empresa:

\begin{abstract}
Na senda da velha lição de Alberto Asquini, em seu clássico trabalho sobre os perfis da empresa, que ensinou ser a empresa um fenômeno poliédrico, não se pode confundir o empresário ou a sociedade empresária (perfil subjetivo) com a atividade empresarial ou organização produtiva (perfil funcional), nem com o estabelecimento empresarial (perfil objetivo ou patrimonial). Nesta linha, busca-se preservar a empresa como atividade, mesmo que haja a falência do empresário ou da sociedade empresária, alienando-a a outro empresário, ou promovendo o trespasse ou o arrendamento do estabelecimento, inclusive à sociedade constituída pelos próprios empregados, conforme previsão do art. 50, VIII e X, da Lei de Recuperação de Empresas e Falências (CALÇAS, 2007, p.40).
\end{abstract}

Assim, apenas com o advento da Lei n. 11.101 de 2005 reelaborou-se o instituto da falência e criou-se a recuperação judicial, distinguindo-se o conceito de empresa e empresário, com o escopo de preservar a organização empresarial que se trouxe para o procedimento falimentar a importância que a empresa desempenha e a busca objetiva de sua preservação em razão dos perfis envolvidos em sua crise econômica, recuperando-se as empresas recuperáveis.

O Decreto-lei n. 7.661/45, que antecedeu à atual legislação, dispunha sobre falências e concordatas, diferentemente da lei em vigor que regula a "a recuperação judicial, a extrajudicial e a falência do empresário e da sociedade empresária".

O procedimento previsto pelo Decreto-Lei n. 7.661 não objetivava 0 soerguimento ou subsistência da empresa, mas disciplinava, tão somente, a execução concursal do comerciante e das sociedades comerciais no processo falimentar, que, em rigor, objetivava a exclusão do agente econômico inadimplente do mercado. A concordata, preventiva ou suspensiva, tinha a natureza jurídica de favor legal, que o Estado, por intermédio do Estado-Juiz, concedia a comerciante, infeliz nos negócios, porém, honesto.

O escopo da lei era, portanto, outro. Não era voltado para soerguer o empresário ou a empresa, não tinha em mira detectar as dificuldades financeiras e operacionais que colocaram em risco a manutenção da organização empresarial. 
O procedimento voltava-se apenas e tão somente para a arrecadação dos bens, expropriação do patrimônio e a administração do passivo com o pagamento dos credores com observância ao princípio da par conditio creditorum. A falência, por seu turno, tinha um viés punitivo, partindo da premissa de que todo o comerciante inadimplente ou insolvente era um fraudador ou incompetente.

Com o procedimento todo voltado à falência, a concordata, como benefício legal, concessivo de moratória ou abatimento parcial do passivo tinha como escopo, prevenir ou suspender os efeitos do decreto de quebra. Confira-se:

Art. 139. A concordata é preventiva ou suspensiva, conforme for pedida em juízo antes ou depois da declaração da falência. Art. 149. Enquanto a concordata não for por sentença julgada cumprida (art. 155), o devedor não pode, sem prévia autorização do juiz, ouvido o representante do Ministério Público, alienar ou onerar seus bens imóveis ou outros sujeitos a cláusulas da concordata; outrossim, sem o consentimento expresso de todos os credores admitidos e sujeitos aos efeitos da concordata, não lhe é permitido vender ou transferir o seu estabelecimento.

Diante de sua finalidade fortemente executiva, funcionava na antiga legislação apenas a figura do síndico como administrador da massa falida, não participando da concordata:

Art. 59. A administração da falência é exercida por um síndico, sob a imediata direção e superintendência do juiz. Art. 60. O síndico será escolhido entre os maiores credores do falido, residentes ou domiciliados no fôro da falência, de reconhecida idoneidade moral e financeira.

Além do fato de o síndico atuar na gestão da massa falida, a legislação revogada também dispunha que caberia ao devedor auxiliar o síndico naquilo que necessário ao deslinde de seu múnus:

Art. 34. A declaração da falência impõe ao falido as seguintes obrigações: $V$ - entregar sem demora todos os bens, livros, papéis e documentos ao síndico, indicando-lhe, para serem arrecadados, os bens que porventura tenha em poder de terceiros; VI - prestar, verbalmente ou por escrito, as informações reclamadas pelo juiz, síndico, representante do Ministério Público e credores, sobre circunstâncias e fatos que interessem à falência; VII - auxiliar o síndico com zelo e lealdade. 
Significa dizer que em vez de o legislador trazer o síndico como um terceiro imparcial capaz de avaliar o processo produtivo e opinar quanto à viabilidade da concordata do devedor, a pesada redação da lei ainda sujeitava o devedor a prestar auxílio ao síndico, aumentando a carga de tarefas e atribuições em uma situação já calamitosa de franco envolvimento pessoal e emocional que é a iminência da falência, situação observada pela doutrina da época:

\begin{abstract}
No vigente Direito positivo brasileiro é marcante a orientação liquidatória não se tendo consagrado ainda a tendência recuperadora, mesmo porque, por ocasião da elaboração da lei, não se levou em conta o fenômeno empresa, com todas as suas complexas implicações. Por outro lado, entre os sistemas legais vanguardeiros em matéria de disciplina dos procedimentos de reorganização ou de reerguimento de empresas, impõese mencionar as leis norte-americanas 'Bankruptcy Code', de 1978, e a francesa de 1985, n. 85-98, que instituiu um procedimento de reerguimento judicial, 'destinado a permitir a salvaguarda da empresa, a manutenção da atividade e do emprego e a apuração do passivo'(art. 1). ...no que concerne ao Direito brasileiro, como imperativo de verdade científico, cumpre proclamar sua absoluta inadequação à atual realidade sócio-econômica a que deve servir: ou se atualiza, passando a regular o reerguimento das empresas em crise, ou está fadado a ser considerado ultrapassado (ABRÃO, 1989, p.45).
\end{abstract}

Com o advento da Lei n. 11.101 de 2005 o paradigma alterou-se, com o legislador voltando os olhos para as necessidades do empresário e do empreendimento empresarial, objetivando auxiliá-lo no soerguimento de sua atividade.

O objetivo principal da atual legislação é detectar e implementar os meios necessários para que a empresa viável se mantenha ativa no mercado e extinguir as empresas inviáveis, o que é imprescindível para a saúde do mercado e dos credores.

Neste sentido o posicionamento de Manoel de Queiroz Pereira Calças (2007, p.41):

O escopo de recuperação da empresa deve ser tentado, exclusivamente, quando for aferido, em juízo, por meio de estudos de viabilidade econômica do empreendimento, que a empresa é tecnicamente recuperável, cabendo então ao Estado, propiciar instrumentos efetivos que permitam sua recuperação. 
Note-se que a lei não é de falências, como o antigo decreto-lei, mas sim regula a recuperação judicial (em primeiro lugar) e a falência (em segundo lugar) do empresário e da sociedade empresária.

De tal sorte, o Poder Judiciário e o administrador judicial, com a participação ativa dos credores, atuam na recuperação judicial de modo a possibilitar que a empresa seja preservada e recuperada, sendo que apenas diante de sua inviabilidade econômica deve ser decretada a falência.

Diferentemente da revogada legislação que disciplinava a participação ativa do síndico apenas no processo de falência (haja vista a atuação meramente fiscalizadora do comissário da concordata), a nova legislação regulamentou a vigorosa participação do administrador judicial em todas as etapas do procedimento recuperacional e falimentar:

\begin{abstract}
Art. 21. O administrador judicial será profissional idôneo, preferencialmente advogado, economista, administrador de empresas ou contador, ou pessoa jurídica especializada. Parágrafo único. Se o administrador judicial nomeado for pessoa jurídica, declarar-se-á, no termo de que trata o art. 33 desta Lei, o nome de profissional responsável pela condução do processo de falência ou de recuperação judicial, que não poderá ser substituído sem autorização do juiz. Art. 22. Ao administrador judicial compete, sob a fiscalização do juiz e do Comitê, além de outros deveres que esta Lei lhe impõe: I - na recuperação judicial e na falência [...] II - na recuperação judicial [...] III na falência [...].
\end{abstract}

Duas grandes diferenças: o síndico era eleito entre os maiores credores da massa falida e atuava no auxílio judicial da falência; na nova lei o administrador judicial é nomeado pelo juiz entre profissionais idôneos e de formação afiliada às necessidades contábeis, jurídicas e de fiscalização financeira.

Diferentemente da revogada lei falimentar, a legislação atual impõe ao administrador judicial um múnus público de auxiliar do juízo, efetivamente subordinado ao magistrado, com franca importância econômica no trabalho por ele desempenhado, razão pela qual a lei se utiliza da condição de confiança estabelecida entre sua figura e a do juiz condutor do processo de recuperação e/ou falência, conforme destacado em decisão judicial proferida pela justiça do Estado do Rio de Janeiro: 


\begin{abstract}
O Administrador Judicial, como se sabe, é um auxiliar do Juízo da recuperação, uma pessoa de confiança do magistrado, que o ajudará na condução do processo. A confiança no trabalho do AJ é fundamental nessa relação, como ressalta a doutrina e a jurisprudência sobre o tema. $E$, em uma recuperação desta magnitude, a maior da América Latina, já bastante complexa por si só, entendo que não agrega valor uma atuação que não prime pela excelência. Não há espaço nem tempo a se perder com a atuação do AJ financeiro. Não cabe ao juízo ficar interferindo para que o trabalho seja feito, com a qualidade que se espera. Isso só traz prejuízos à condução do processo de recuperação, aos credores e às devedoras ${ }^{3}$.
\end{abstract}

E esta relação de confiança se deve ao fato de não ser exigível dos membros do Poder Judiciário o conhecimento das áreas contábeis e afins do saber, de modo que o magistrado não possui condições de continuadamente rever os trabalhos realizados pelo administrador judicial.

No Direito Francês, a exemplo do sistema brasileiro, no procedimento de recuperação judicial de empresa, a figura do administrador judicial ganha destaque na fiscalização do cumprimento do plano aprovado pelos credores, na preservação e defesa do patrimônio empresarial - garantia única dos credores - contra a conduta fraudulenta dos gestores da empresa, senão vejamos:

Article L631-10-1. A la demande de l'administrateur ou du mandataire judiciaire, le président du tribunal saisi peut ordonner toute mesure conservatoire utile à l'égard des biens du dirigeant de droit ou de fait à l'encontre duquel l'administrateur ou le mandataire judiciaire a introduit une action en responsabilité fondée sur une faute ayant contribué à la cessation des paiements du débiteur. ${ }^{4}$

A lei brasileira também contempla a capacidade postulatória do administrador judicial para, em defesa da coletividade de credores e com o escopo de preservação da empresa, propor ações judiciais visando à declaração judicial de ineficácia e à revogação de atos jurídicos praticados pelos gestores da empresa recuperanda ou falida.

\footnotetext{
${ }^{3}$ Recuperação Judicial da OI S.A. Processo n. 0203711-65.2016.8.19.0001 - 7ª Vara Empresarial da Comarca da Capital - Rio de Janeiro. Juiz de Direito Fernando Cesar Ferreira Viana, fls. 187.620.

${ }^{4}$ Tradução livre: A pedido do administrador judicial, o presidente do tribunal competente pode ordenar qualquer medida para conservação dos bens dos gestores de direito ou de fato, contra os quais o administrador judicial tenha interposto uma ação de responsabilidade civil subjetiva contribuindo com o término dos pagamentos do devedor.
} 
Todas as funções do administrador judicial denotam a importância do mister por ele desempenhado, porém, destacam a natureza social e a finalidade coletiva do trabalho realizado, que não se resume à simples tarefa de mandatário ou procurador, mas encontra transcendência diante da repercussão que a empresa representa dentro de uma determinada comunidade.

Essa natureza social que permeia a função do administrador judicial dentro do contexto da teoria da empresa e seu perfil poliédrico exige acurado estudo a respeito da remuneração que deve - e pode - ser paga ao profissional ou pessoa jurídica que são indicados para cuidar da recuperação judicial ou falência.

No tópico seguinte examinaremos a legislação brasileira e os critérios nela previstos para a fixação do pagamento de remuneração ao administrador judicial, os parâmetros e o controle exercido pelo juiz responsável pela condução do processo de recuperação e falência.

\section{A REMUNERAÇÃO DO ADMINISTRADOR JUDICIAL NA LEGISLAÇÃO BRASILEIRA}

Calha, inicialmente, o registro histórico da variante proporcional que compunha a fixação da remuneração da antiga figura do síndico da massa falida sob a égide do Decreto-Lei n. 7.661/45:

Art. 67. O síndico tem direito a uma remuneração, que o juiz deve arbitrar, atendendo à sua diligência, ao trabalho e à responsabilidade da função e à importância da massa, mas sem ultrapassar de $6 \%$ até Cr $\$ 100.000,00$; de $5 \%$ sôbre o excedente até $\operatorname{Cr} \$ 200.000,00$; de $4 \%$ sôbre o excedente até Cr $\$ 500.000,00$; de $3 \%$ sôbre o excedente até $\operatorname{Cr} \$ 1.000 .000,00$; de $2 \%$ sôbre o que exceder de $\operatorname{Cr} \$ 1.000 .000,00$.

No que concerne ao comissário, previa o antigo artigo 170 da legislação que teria ele direito a uma remuneração, que o juiz deveria arbitrar atendendo à sua diligência, ao trabalho, à responsabilidade da função e à importância da concordata, 
calculando-se sobre o valor do pagamento prometido aos credores quirografários e sendo ela limitada à terça parte das percentagens previstas no art. 67.

$\mathrm{Na}$ esteira da redação dos dispositivos revogados, quanto maior o crédito discutido, menor seria a alíquota de forma a tornar proporcional o valor a ser percebido, de sorte que não houvesse discrepância de grande relevo entre os valores percebidos pelo síndico em diferentes falências ou concordatas.

Os parâmetros legais, mínimo e máximo de $2 \%$ e $6 \%$ eram insuperáveis, de tal sorte que nenhum critério justificaria a fixação da remuneração em desacordo aos preceitos legais, conforme entendimento jurisprudencial. ${ }^{5}$

Também houve situação na qual o síndico foi condenado em restituir o valor que recebeu a maior. Conforme se verá mais adiante é costumeira a fixação da remuneração do síndico, hoje administrador judicial, em quantia mensal enquanto tramitar a falência ou concordata, hoje, recuperação judicial.

Dessa forma, sob a vigência da antiga legislação, caso o síndico percebesse montante acumulado superior aos percentuais fixados, então deveria ser compelido a restituir à massa a quantia excedente a fim de se evitar o enriquecimento indevido. 6

O legislador de 2005 não andou tão bem. Não fixou base de cálculo sobre a qual deveriam incidir alíquotas progressivas, senão fixou somente o percentual máximo de 5\%:

\begin{abstract}
Art. 24. O juiz fixará o valor e a forma de pagamento da remuneração do administrador judicial, observados a capacidade de pagamento do devedor, o grau de complexidade do trabalho e os valores praticados no mercado para o desempenho de atividades semelhantes. $\S 1 \underline{0}$ Em qualquer hipótese, o total pago ao administrador judicial não excederá $5 \%$ (cinco por cento) do valor devido aos credores submetidos à recuperação judicial ou do valor de venda dos bens na falência.
\end{abstract}

\footnotetext{
${ }^{5}$ Ementa: Falência. Decreto-Lei n. 7.661/45. Remuneração do síndico. Art. 67. Percentual máximo. Base de cálculo. Recurso provido. Tribunal de Justiça do Paraná, 17ª Câmara Cível. Relator Des. Lauri Caetano da Silva. Acórdão 111293-6. DJ 03/06/2014.

${ }^{6}$ Agravo de Instrumento. Falência. Remuneração do Síndico. Trabalho técnico realizado pela assessoria contábil do MP para apuração do valor correto a ser pago. Constatação de excesso. Restituição. Possibilidade jurídica. Tribunal de Justiça do Rio Grande do Sul, recurso 70061134623, Quinta Câmara Cível, Rel. Des. Jorge Luiz Lopes do Canto, DJ 10/12/2014.
} 
Conclui-se da redação legal que não há limitação na base de cálculo que conduza a fronteiras para a incidência da alíquota que pode chegar a até $5 \%$ do valor do crédito ou dos bens arrecadados com a massa falida.

Diante dessa lacuna coube à jurisprudência fornecer elementos para a compreensão do papel do administrador judicial como auxiliar do juiz, e, nessa condição pautar os limites do crédito que pode receber. Incidem nesta tarefa do juiz os princípios da proporcionalidade, razoabilidade e equidade.

A recuperação judicial não é do administrador judicial, assim como não o é a falência. Os atores principais são as empresas falidas ou em recuperação judicial, que estão imersas em crise econômico-financeira e, nesta condição, não podem ser compelidas a arcar com valores astronômicos para pagar o trabalho, imprescindível e honesto, dos indispensáveis administradores judiciais. Os objetivos primordiais do processo de falência e de recuperação judicial são: pagar os credores, da forma mais justa e equânime possível e, se a situação econômico-financeira permitir, soerguer o empreendimento empresarial, cumprindo-se, destarte, o princípio da preservação da empresa.

Com o advento da Lei n. 11.101/05, que trouxe a nova regulamentação da Recuperação Judicial e Falência, o Tribunal de Justiça de São Paulo foi pioneiro na criação de um órgão específico para decidir os recursos e incidentes afetos à matéria em 2005.

Por isso foram reunidos julgadores especializados no julgamento das empresas em crise, preferencialmente aqueles que, além da formação jurídica, também ostentam notória expertise na área contábil, financeira e econômica para a análise mais adequada dos relatórios e pareceres contábeis atrelados aos processos de recuperação e falências.

Com a concentração dos julgamentos recursais na Câmara Reservada à Falência e Recuperação Judicial (atualmente são duas Câmaras especializadas) o Tribunal de Justiça do Estado de São Paulo propiciou intenso e profundo debate técnico em torno da hermenêutica hodierna da Lei n. 11.101/05. 
Concernente ao tema da remuneração do administrador judicial, a Câmara Reservada de Falências e Recuperações do Tribunal de Justiça paulista, em acórdão inaugural e unânime, de forma criativa limitou a remuneração do administrador ao teto do funcionalismo público estadual previsto na Constituição Federal, conforme acórdão de lavra do Des. Manoel de Queiroz Pereira Calças:

\begin{abstract}
Administrador Judicial. Remuneração. Recuperação Judicial. Auxiliar do Juiz. Inteligência dos artigos 24 e 63, I, da LRF. Momento e critérios para fixação da remuneração total. Possibilidade do arbitramento ser realizado pelo Juiz, quando do deferimento do processamento da recuperação. Fixação do valor total, bem como da remuneração mensal, a ser paga pela sociedade empresária a título de adiantamento. Aplicação dos princípios constitucionais que limitam a remuneração dos membros e servidores do Poder Judiciário, sob a óptica dos postulados da proporcionalidade e razoalidade. Teto máximo: vencimentos de Desembargador de Tribunal de Justiça, haja vista que o administrador é auxiliar do Juiz estadual. Reserva de $40 \%$ do montante total devido, para ser paga ao administrador judicial após a prestação de contas e aprovação do relatório final (Tribunal de Justiça do Estado de São Paulo. Agravo de Instrumento n. 903685804.2005.8.26.0000. Câmara Especial de Falências e Recuperações Judiciais de Direito Privado. Rel. Des. Pereira Calças. DJ 25/04/2007).
\end{abstract}

Com aludido entendimento, a jurisprudência trouxe um critério econômico para limitação da remuneração prevista pela lei que fixou apenas a alíquota máxima de $5 \%$ sem quantificação em valores reais.

Dessa forma, ao fixar a remuneração do administrador judicial, levando em conta a natureza de suas funções de auxiliar do juízo e, portanto, subordinado ao teto dos subsídios dos magistrados, supre a lacuna deixada pelo legislador, que não previu, diferentemente da lei anterior, valores máximos sobre os quais a alíquota poderia incidir.

Para além de estabelecer valor máximo da remuneração do administrador judicial, o precedente citado reconhece, com clareza, que o administrador judicial, na condição de auxiliar do juiz, não pode receber mensalmente, honorários por sua atuação nos processos falimentares ou recuperacionais, que superem os subsídios mensais da magistratura estadual.

Importante ressaltar que administrador judicial não atua de forma independente no processo, não aprova planos, não administra a empresa em 
recuperação, não assume o encargo de gestor ou administrador da empresa recuperanda, não profere qualquer decisão administrativa ou econômica, uma vez que todas as providências passam pelo crivo do juiz ou da assembleia de credores, que podem acarretar a falência ou a recuperação da empresa. Destaque-se que a empresa em recuperação, em regra, continua a ser administrada por seus diretores ou administradores estatutários ou contratuais.

Pouco tempo depois da prolação do acórdão pioneiro pelo Tribunal de Justiça de São Paulo, também o Superior Tribunal de Justiça veio a sufragar a tese de que o administrador judicial não atua com a independência do profissional jurídico ou contábil, mas submetido ao juiz:

O síndico, assim como seu sucedâneo - administrador judicial - não exerce profissão. Suas atividades possuem natureza jurídica de órgão auxiliar do Juízo, cumprindo verdadeiro múnus público, não se limitando a representar o falido ou mesmo seus credores. Cabe-lhe, desse modo, efetivamente, colaborar com a administração da Justiça (REsp 1032960/PR, rel. Min. MASSAMI UYEDA, j. 01.06.2010).

Assim, em sendo o administrador judicial simples órgão auxiliar do juízo, justifica-se o posicionamento no sentido de que sua remuneração, observado o limite de $5 \%$ previsto pela lei (art. $24, \S 1^{\circ}$ ), não ultrapasse, mensalmente, durante o processamento da recuperação judicial, o teto mensal dos subsídios pagos à magistratura estadual, na medida em que compete a esta, nos termos do artigo 109, I, da Constituição Federal, o processamento das falências e recuperações judiciais.

Examinada a legislação e a intepretação jurisprudencial mencionada, no próximo capítulo será analisada a legislação comparada como fonte para reflexão acerca da necessidade de fixação de limites à remuneração do órgão e administração judicial da falência e recuperação. 


\section{A REMUNERAÇÃO DO ADMINISTRADOR JUDICIAL NO DIREITO ESTRANGEIRO}

O Direito Empresarial, e não apenas este ramo, sofre as interferências do meio social no qual tem suas leis editadas e é interpretado por tribunais à luz da situação econômica de determinado período histórico.

Por isso, estudar o direito e ordenamento jurídico de outros países tem como objetivo fornecer subsídios para o aprofundamento científico da área do conhecimento e possibilitar o progresso com a modificação e adequação às situações variadas.

Com isso, o método comparativo deve ser adotado pelo operador do direito com a finalidade de trazer a estrutura e mecanismos utilizados por outros povos para a regulamentação de um mesmo tema, conforme destaca René David (1950, p.683):

O direito comparado é um instrumento essencial de cultura geral para o
jurista, porque sem ele, como sem a história da qual ele é complemento e
homólogo, sem ele não é possível chegar a conclusões que ultrapassam a
porta do direito particular e não se pode encontrar a universalidade que
postula toda verdadeira ciência.

No tocante ao tema da atuação do administrador judicial da recuperação judicial e falência no Brasil, é possível trazer à baila o exame de dispositivos da legislação da Itália, Colômbia, França, Portugal e Estados Unidos, para a comparação dos sistemas legais em vigor.

Curiosamente, constatar-se-á que os diplomas estrangeiros trabalham com limitação percentual e de base de cálculo, estabelecendo, portanto, maior controle do valor que deve ser pago a título de remuneração do administrador judicial, síndico ou comissário, conforme a denominação adotada.

$\mathrm{Na}$ Itália, a remuneração do administrador da massa falida é regulada pelo Decreto n. 25 de janeiro de 2012 que regulamenta o disposto no Decreto Real de 16 de março de 1942, dispondo que: 


\begin{abstract}
Art. 1ํ. A indenização ao administrador da massa falida é liquidada pelo tribunal em conformidade com o artigo 39 do Real Decreto de 16 de março de 1942, n. 267, tendo em conta o trabalho realizado, os resultados obtidos, a importância do fracasso, bem como a solicitude com que as operações relacionadas foram conduzidas e devem consistir de uma percentual sobre o valor do ativo realizado não superior ao seguintes medidas: a) de $12 \%$ para $14 \%$ quando o ativo não exceda $€ 16.227,08$; b) de $10 \%$ a $12 \%$ sobre montantes superiores a $16.227,08$ euros até $24.340,62 €$; c) de $8,50 \%$ para $9,50 \%$ sobre montantes superiores a $24.340,62$ euros até $40.567,68$ euros; d) de $7 \%$ a $8 \%$ sobre montantes superiores a $40.567,68$ euros até $81,135.38$ euros; e) de $5,5 \%$ para $6,5 \%$ sobre montantes superiores a $81,135,38$ euros até 405676,89 euros; f) de $4 \%$ a $5 \%$ sobre quantias superiores a $405.676,89 €$ até $€ 811.353,79 ; \mathrm{g})$ de $0,90 \%$ para $1,80 \%$ sobre montantes superiores a $€ 811.353,79$ até $€ 2.434 .061,37$; h) de $0,45 \%$ a $0,90 \%$ em valores superiores a 2.434.061,37 €. [...] Art. 3ำ1. Quando a continuação da actividade é autorizada da empresa falida para o administrador é pago, para além da remuneração referida nos artigos $1^{\circ}$ e $2^{\circ}$, uma nova remuneração do $0,50 \%$ sobre o lucro líquido e $0,25 \%$ sobre a receita bruta alcançado durante o exercício provisório.
\end{abstract}

Para exemplificação, adotando a última hipótese de remuneração do administrador judicial, para ativo de 10 milhões a porcentagem aplicada variará de 0,45 a 0,90\%, logo, o mínimo será 45.000 e o máximo 90 mil euros.

Em Portugal a Lei n. 32/2004, prevê que o administrador da insolvência terá o direito de ser remunerado pelos atos praticados de acordo com montante estabelecido pelos Ministros das Finanças e da Justiça.

Nesta linha, os Ministérios das Finanças e da Administração Pública e da Justiça aprovaram a Portaria 51/2005 que fixa a tabela com base de cálculo e alíquota de remuneração do administrador da insolvência:

Art. 1. O Valor fixo da remuneração. $1-O$ valor da remuneração do administrador da insolvência nomeado pelo juiz, nos termos do no 1 do artigo $20^{\circ}$ da Lei $n^{\circ} 32 / 2004$, de 22 de Julho, que aprovou o estatuto do administrador da insolvência, é de (euro) 2000. 2 - No caso de o administrador da insolvência exercer as suas funções por menos de seis meses devido à sua substituição por outro administrador, aquele terá direito somente à primeira das prestações referidas no no 2 do artigo $26^{\circ}$ da Lei $n^{\circ}$ $32 / 2004$, de 22 de Julho, que aprovou o estatuto do administrador da insolvência. $2^{\circ}$ Tabelas de remuneração variável são aprovadas, em anexo à presente portaria, as tabelas que estabelecem a remuneração variável do administrador da insolvência, nos termos dos nos 2 a 4 do artigo $20^{\circ}$ da Lei no 32/2004, de 22 de Julho, que aprovou o estatuto do administrador da insolvência. 


\begin{tabular}{|c|c|c|}
\hline \multicolumn{3}{|c|}{$\begin{array}{l}\text { ANEXOI } \\
\text { Tabela a que se refere o } n .^{\circ} 2 \text { do artigo } 20 .^{\circ} \text { da Lei n. }{ }^{\circ} 32 / 2004, \\
\text { de } 22 \text { de Julho, que aprovou o estatuto do administrador } \\
\text { da insolvência. }\end{array}$} \\
\hline $\begin{array}{l}\text { Escalōes } \\
\text { (em euros) }\end{array}$ & $\begin{array}{c}\text { Taxa base } \\
\text { (em percentagem) }\end{array}$ & $\underset{\text { (em pereentagem) }}{\text { Taxa marginal }}$ \\
\hline $\begin{array}{l}\text { Até } 15000 \ldots \ldots \\
\text { De } 15000,01 \text { até } 50000 \ldots \ldots \ldots \ldots \\
\text { De } 50000,01 \text { até } 150000 \ldots \ldots \ldots \\
\text { De } 150000,01 \text { até } 250000 \ldots \ldots \ldots \\
\text { De } 250000,01 \text { até } 500000 \ldots \ldots \ldots \\
\text { De } 500000,01 \text { até } 1000000 \ldots \ldots \ldots \\
\text { De } 1000000,01 \text { até } 2000000 \ldots \ldots \\
\text { De } 2000000,01 \text { até } 5000000 \ldots \ldots \\
\text { De } 5000000,01 \text { até } 7500000 \ldots \ldots \\
\text { Superior a } 7500000 \ldots \ldots \ldots\end{array}$ & $\begin{array}{l}7 \\
5,5 \\
3 \\
2,5 \\
2 \\
1,25 \\
0,5 \\
0,45 \\
0,3 \\
0,1\end{array}$ & $\begin{array}{l}7 \\
5,95 \\
3,983 \\
3,39 \\
2,695 \\
1,9725 \\
1,2363 \\
0,6745 \\
0,5297\end{array}$ \\
\hline
\end{tabular}

A lei lusitana divide a remuneração do administrador em duas classes: Fixa e Variável. A remuneração fixa é de 2 mil euros, além da remuneração variável de acordo com os montantes indicados na tabela acima.

Dessa forma, usando o mesmo exemplo de uma falência com valor envolvido de 10 milhões, o administrador faz jus à percepção de remuneração variável de 10 mil euros, mais a remuneração fixada de 2 mil euros.

Na América do Sul, a Colômbia formula interessante legislação a respeito da remuneração do promotor de insolvência, conforme a denominação adotada pela Lei n. 1.116 de 2006.

O tema da remuneração do promotor da insolvência é regulamentado pelo Decreto n. 991 de 2018, que impõe ao juiz a fixação dos honorários logo quando da abertura do processo de insolvência, senão vejamos: 


\begin{tabular}{|c|c|c|}
\hline \multicolumn{3}{|c|}{ REMUNERACIÓN TOTAL } \\
\hline $\begin{array}{l}\text { Categoría de la } \\
\text { entidad en proceso } \\
\text { de reorganización }\end{array}$ & $\begin{array}{l}\text { Rango por activos } \\
\text { en salarios } \\
\text { minimos legales } \\
\text { mensuales } \\
\text { vigentes }\end{array}$ & $\begin{array}{l}\text { Límite para la } \\
\text { fijación del valor } \\
\text { total de honorarios }\end{array}$ \\
\hline A & Más de 45.000 & $\begin{array}{lr}\text { No podrán } & \text { ser } \\
\text { superiores } & \text { a } \\
440 \text { smimv. } & \end{array}$ \\
\hline $\mathrm{B}$ & $\begin{array}{l}\text { Más de } 10.000 \\
\text { hasta } 45.000\end{array}$ & $\begin{array}{lr}\text { No podrán ser } \\
\text { superiores } \\
240 \text { smlmv. }\end{array}$ \\
\hline $\mathrm{C}$ & Hasta 10.000 & $\begin{array}{lr}\text { No podrán } & \text { ser } \\
\text { superiores } & \text { a } \\
120 \text { smlmv. } & \end{array}$ \\
\hline
\end{tabular}

Note-se que, do mesmo modo, a lei colombiana limita o valor dos honorários do promotor da insolvência em valor máximo equivalente ao salário mínimo vigente. Nisso repousa uma grande vantagem, pois, considerando que o salário mínimo é constantemente atualizado, evita-se a depreciação da remuneração. Outrossim, para o Brasil este sistema não seria possível, uma vez que a Constituição Federal veda a vinculação para qualquer fim (art. $7^{\circ}$, inciso IV).

Exemplificando, caso o valor do ativo seja de 10.000 salários mínimos, a remuneração do promotor da insolvência não poderá ser superior a 120 salários mínimos, evitando-se o enriquecimento.

No Direito Francês ${ }^{7}$, igualmente a previsão legal do Código de Comércio, regula conforme as fases do procedimento de reestruturação, o valor devido pela remuneração do administrador judicial.

Assim, na fase de elaboração do plano, o administrador judicial faz jus à remuneração calculada levando em conta o número de empregados que o devedor possua e o número de salários pagos:

\footnotetext{
${ }^{7}$ Para mais, consultar: Institut Français des Praticiens des Procédures Collectives. Disponível em: http://www.ajup.fr/pdf/TarifAJ2018.pdf. Acesso em: 18.01.2019.
} 


\begin{tabular}{|c|c|c|}
\hline \hline Nombre de salariés & Chiffre d'affaires & Émolument \\
\hline De 0 à 5 & De 0 à $750000 €$ & $902,50 €$ \\
De 6 à 19 & De 750001 à $3000000 €$ & $1805 €$ \\
De 20 à 49 & De 3000001 à $7000000 €$ & $3610 €$ \\
\hline De 50 à 149 & De 7000001 à $20000000 €$ & $7220 €$ \\
À compter de 150 & Au-delà de $20000000 €$ & $9025 €$ \\
\hline \hline
\end{tabular}

Já na fase de encerramento, quando o plano de reorganização é aprovado, o administrador faz jus à remuneração calculada nos ditames do artigo 663-8 do Código de Comércio Francês, nos termos da tabela abaixo:

\begin{tabular}{|c|c|c|}
\hline \hline Nombre de salariés & Chiffre d'affaires & Émolument \\
\hline De 0 à 5 & De 0 à $750000 €$ & $1353,75 €$ \\
De 6 à 19 & De 750001 à $3000000 €$ & $1805 €$ \\
De 20 à 49 & De 3000001 à $7000000 €$ & $5415 €$ \\
De 50 à 149 & De 7000001 à $20000000 €$ & $9025 €$ \\
À compter de 150 & Au-delà de $20000000 €$ & $13537,50 €$ \\
\hline
\end{tabular}

Note-se, mais uma vez, a marcante limitação imposta pelo legislador, no sentido de que a remuneração máxima do administrador judicial é fixada em $€$ 13.537,50, com o claro intuito de evitar o enriquecimento em prejuízo da massa de credores.

Derradeiramente, no direito estadunidense não passa despercebida a intenção do legislador em limitar a remuneração devida ao trustee, conforme disposto no Chapter 3, Subchapter II: Officers, Title 11, Bankruptcy Chapter 3 - Case Administration:

\$326. Limitation on compensation of trustee. (a) In a case under chapter 7 or 11, the court may allow reasonable compensation under section 330 of this title of the trustee for the trustee's services, payable after the trustee renders such services, not to exceed 25 percent on the first $\$ 5,000$ or less, 10 percent on any amount in excess of $\$ 5,000$ but not in excess of $\$ 50,000,5$ percent on any amount in excess of $\$ 50,000$ but not in excess of $\$ 1,000,000$, and reasonable compensation not to exceed 3 percent of such moneys in excess of $\$ 1,000,000$, upon all moneys disbursed or turned over in the case by the trustee to parties in interest, excluding the debtor, but including 
holders of secured claims. ${ }^{8}$

Mais uma vez, o legislador atrelou o valor percentual a uma base de cálculo, evitando que, sem limite de incidência, a base de cálculo se traduza em valores exorbitantes, prejudicando a empresa em recuperação e a massa de credores.

\section{ANÁLISE DOS MAIORES CASOS DE RECUPERAÇÃO JUDICIAL E FALÊNCIA DO BRASIL}

Em 2013, o CNJ - Conselho Nacional de Justiça - arquivou pedido de providências no qual se apurava a alegada irregularidade na nomeação de administrador judicial repetidamente em casos de recuperação judicial e falências.

Entre os casos que incitaram a instauração do procedimento está o caso da Varig Logística, no qual o administrador judicial era remunerado mensalmente com o valor de $\mathrm{R} \$ 75$ mil (CONJUR, 2013).

Em que pese o arquivamento, imperioso destacar que em 2013 a remuneração do Desembargador do Tribunal de Justiça de São Paulo era de aproximadamente $\mathrm{R} \$ 25$ mil, conforme Portal da Transparência. 9

Logo, a remuneração do administrador judicial naquele caso polêmico equivalia, à época, ao triplo da remuneração dos juízes responsáveis pela condução dos procedimentos de falência e recuperação judicial em segundo grau de jurisdição.

Em análise comparativa dos maiores casos de recuperação judicial que o país já teve, o administrador judicial do caso "Oi Telefonia" foi remunerado com o

\footnotetext{
8Tradução livre: Seção 326. Limitação da remuneração do administrador. Nos casos previstos nos capítulos 7 ou 11, a corte pode permitir uma indenização razoável sob a seção 330 deste título do agente fiduciário para os serviços do administrador, pagáveis depois que administrador prestar os serviços, não excedendo $25 \%$ sobre os primeiros US $\$ 5.000$ ou menos, 10 por cento em qualquer quantia acima de US $\$ 5.000$, mas não acima de US $\$ 50.000$, $5 \%$ sobre qualquer quantia superior a US \$50.000, mas não acima de US \$1.000.000, e uma compensação razoável que não exceda $3 \%$ desses montantes que excedam de US $\$ 1.000 .000$, sobre todos os valores desembolsado ou entregue pelo administrador às partes interessadas, excluindo o devedor, mas incluindo os detentores de créditos garantidos.

9Disponível em: http://www.tjsp.jus.br/RHF/PortalTransparencial. Acesso em: 19.01.2018.
} 
valor de $\mathrm{R}$ \$ 141 milhões, e no caso "OGX" a remuneração ficou em $\mathrm{R}$ \$ 15 milhões, conforme quadro estatístico a seguir apresentado:

\begin{tabular}{|c|c|c|c|c|c|}
\hline EMPRE SA & COMARCA & PROCESSO & ADMINISTRADOR & REMUNERAÇÄO & DIVIDA \\
\hline OI TELEFONIA & $\begin{array}{c}7^{\mathrm{a}} \text { Vara } \\
\text { Empresarial - Rio } \\
\text { de Janeiro }\end{array}$ & $\begin{array}{c}0203711- \\
65.2016 .8 .19 .0001\end{array}$ & PwC e WALD & 141,29 milhốes & 7,31 bilhốes \\
\hline PARMALAT & $\begin{array}{l}1^{\mathrm{a}} \text { Vara de } \\
\text { Falências da } \\
\text { Capital - SP }\end{array}$ & $000.05 .068 .090-0$ & Alfre do Luis Kugelmas & 50 mil mensais & 2,2 bilhões \\
\hline MONDELLI & $\begin{array}{c}1^{8} \text { Vara Civel de } \\
\text { Bauru - SP }\end{array}$ & $\begin{array}{c}0004265- \\
12.2012 .8 .26 .0071 \\
\end{array}$ & Fernando José Ramos Borges & $1 \%$ & 57,4 milhões \\
\hline OAS & $\begin{array}{c}1^{\mathrm{a}} \text { Vara de } \\
\text { Falências da } \\
\text { Capital - SP }\end{array}$ & $\begin{array}{c}1030812- \\
77.2015 .8 .26 .0100\end{array}$ & Alvarez \& Marsal & 3,6 milhões & 11,1 bilhões \\
\hline SARAIVA & $\begin{array}{l}2^{\mathrm{g}} \text { Vara de } \\
\text { Falências da } \\
\text { Capital - SP }\end{array}$ & $\begin{array}{c}1119642- \\
14.2018 .8 .26 .0100\end{array}$ & Lucon Advogados & 100 mil mensais & 675 milhões \\
\hline SCHAHIN & $\begin{array}{c}2^{\mathrm{a}} \text { Vara de } \\
\text { Falências da } \\
\text { Capital - SP }\end{array}$ & $\begin{array}{c}1037133- \\
31.2015 .8 .26 .0100\end{array}$ & KPMG Corporate Finance LTDA & $0,09 \%$ da dívida $=5.265 .633,72$ & 6,5 bilhões \\
\hline UTC & $\begin{array}{l}2^{\mathrm{a}} \text { Vara de } \\
\text { Falências da } \\
\text { Capital - SP }\end{array}$ & $\begin{array}{c}1069420- \\
76.2017 .8 .26 .0100\end{array}$ & Laspro Consultores Ltda & $\begin{array}{c}\text { (i) pagamento de R\$ } \\
1.050 .000,00 \text { e de R\$ } 750.000,00 \\
\text { pela atuação até a AGC; (ii) } \\
\text { pagamentos mensais de R\$ } \\
132.000,00 \text {, até o encerramento } \\
\text { do processo }\end{array}$ & 3,4 bilhões \\
\hline OGX & $\begin{array}{c}4^{\mathrm{s}} \text { Vara } \\
\text { Empresarial - Rio } \\
\text { de Janeiro }\end{array}$ & $\begin{array}{c}0377620- \\
56.2013 .8 .19 .0001\end{array}$ & Deloitte e Touche & 15,6 milhões & 11,2 bilhões \\
\hline PDG & $\begin{array}{c}1^{8} \text { Vara de } \\
\text { Falências - SP }\end{array}$ & $\begin{array}{c}1016422- \\
34.2017 .8 .26 .0100 \\
\end{array}$ & $\begin{array}{l}\text { PricewaterhouseCoopers } \\
\text { Assessoria Empresarial Ltda }\end{array}$ & 5,6 milhões & 6,2 bilhões \\
\hline ABENGOA & $\begin{array}{l}\text { Vara Unica de } \\
\text { Santa Cruz das } \\
\text { Palmeiras - SP }\end{array}$ & $\begin{array}{c}1001163- \\
43.2017 .8 .26 .0538\end{array}$ & R4C - EMPRESARIAL & $8.208 .534,50$ & 820 milhões \\
\hline
\end{tabular}

Note-se que, seja nos casos em que a remuneração foi fixada mensalmente ou em percentual sobre o valor do crédito recuperando ou valor de venda dos bens da massa, sempre se superou em muito o valor do teto dos servidores públicos.

Os maiores casos trazem a lume o distanciamento da real função do administrador judicial, que é de mero auxiliar do juízo, e não como protagonista principal do processo que deva receber honorários por serviços de auxiliar do Poder Judiciário que levem em conta o valor do passivo da recuperanda ou dos bens vendidos na execução concursal.

\section{CONCLUSÃO}

A recuperação judicial é o instituto legal previsto para a superação judicial da crise econômico financeira dos empresários e sociedades empresárias que buscam 
o Poder Judiciário para, com o apoio dos credores, soerguerem a empresa para que esta volte a ser uma fonte produtora, com a manutenção dos empregos dos trabalhadores, protegendo-se os interesses dos credores, de modo a preservar a empresa, sua função social, além de promover o estímulo à atividade econômica.

Segundo levantamento estatístico, a partir de 2015, houve sensível aumento dos pedidos de recuperação judicial formulados ao Judiciário brasileiro, atingindo em 2016 a marca de 1.863 novos processos (VALOR, 2017).

Levantamento feito no ano de 2013 demonstrou que apenas 1\% das empresas que entraram na justiça para obter a renegociação de suas dívidas conseguiu êxito no processo de recuperação judicial. ${ }^{10}$

Estes números demonstram que o processo de recuperação judicial é importante para salvar as empresas brasileiras, já que os agentes econômicos são os atuantes diretos e protagonistas da estruturação e manutenção do mercado, que é patrimônio nacional e deve ser incentivado de modo a viabilizar o desenvolvimento cultural, socioeconômico, o bem-estar da população e a autonomia tecnológica do País, conforme expressamente previsto no art. 219 da Constituição Federal.

O pedido, os relatórios iniciais de diagnóstico, o plano de recuperação, o contato com credores, essas e muitas outras providências extrajudiciais e judiciais são elaborados pela recuperanda ou pelo falido.

O ápice do processo de recuperação judicial se dá com a apresentação do plano de recuperação no qual a recuperanda - por meio de seus acionistas ou sócios - demonstra a viabilidade do negócio e apresenta, de forma técnica, econômica e administrativa, a saída para sua situação de crise.

Elaborar o plano de recuperação judicial exige do empresário auto avaliação e autocrítica, para reconhecer onde e como errou, se, de fato errou ou foi vítima do imponderável das crises econômico-financeiras e como pretende superar a situação de crise, sob a ótica do postulado da preservação da empresa.

10 Disponível em: https://economia.estadao.com.br/noticias/geral,so-1-das-empresas-sai-darecuperacao-judicial-no-brasil-imp-,1085558. Acesso em: 19.01.2019. 
O administrador judicial é o auxiliar do juiz. A ele compete consolidar o quadro geral de credores, fiscalizar as atividades do devedor e o cumprimento do plano, presidir a assembleia de credores, etc.

Significa dizer, o administrador judicial não atua com independência profissional ou como consultor, mas como auxiliar do juiz, podendo exercer a função de perito, economista e contador do juízo.

De tal sorte, atuando como auxiliar, o administrador judicial atua com o escopo de soerguer a empresa, mercê do que não pode pleitear para si remuneração exorbitante, abusiva ou que extrapole os honorários razoáveis para suas funções, sob pena de contribuir para a falência do devedor.

O critério legal de atrelar a remuneração, exclusivamente, ao valor devido aos credores submetidos à recuperação judicial ou ao valor da venda dos bens na falência, sem levar em conta a capacidade de pagamento do devedor, o grau de complexidade do trabalho e os valores praticados no mercado para o desempenho de atividades semelhantes, bem como observar sua função de auxiliar do juízo, pode implicar o enriquecimento sem causa dos profissionais que exercem a importante função dos administradores judiciais. Evidente a vulneração dos postulados da proporcionalidade e razoabilidade.

A legislação comparada mencionada neste ensaio vincula a alíquota a valor máximo que pode ser arbitrado, evitando, desta forma, situações de injustiça e de enriquecimento indevido daquele que tem a função de atuar como auxiliar do juízo e não como predador da empresa devedora.

A legislação brasileira não prevê valor econômico máximo, de tal sorte que a jurisprudência paulista mencionada aponta um critério justo e equanime de limitação baseado no teto de remuneração da magistratura estadual.

É preciso reavivar o precedente do Tribunal de Justiça Paulista, para o fim de limitar a remuneração do administrador ao valor máximo da remuneração dos magistrados responsáveis por conduzir o caso de recuperação judicial e falências, enquanto não se tenha reforma na Lei n. 11.101/05 para corrigir a lacuna neste polêmico ponto. 


\section{REFERÊNCIAS}

ABRÃO, Nelson. Curso de direito falimentar. 3. ed. São Paulo: Editora Revista dos Tribunais, 1989.

ASQUINI, Alberto. Perfis da Empresa. Tradução de Fábio Konder Comparato. Revista de Direito Mercantil. vol. 104, out-dez/1996, págs. 109/126.

BEZERRA FILHO, Manoel Justino. Jurisprudência da Nova Lei de Recuperação de Empresas e Falências. São Paulo: RT, 2006.

BERNIER, Joice Ruiz. Administrador Judicial. São Paulo: Quartier Latin, 2016.

CALÇAS, Manoel de Queiroz Pereira. A nova lei de recuperação de empresas e falência: repercussão no Direito do Trabalho (Lei n. 11.101, de 9 de fevereiro de 2005). Rev. TST, Brasília, vol. 73, n 4, out/dez 2007.

CALÇAS, Manoel de Queiroz Pereira. Sociedade Limitada no Novo Código Civil. Ed. Atlas, São Paulo, 2003.

CARAM JUNIOR, Moacyr. Processo de Execução. As excludentes de responsabilidade e o princípio da dignidade humana. Campinas: Bookseller, 2009.

COELHO, Fábio Ulhoa. Manual de Direito Comercial. São Paulo: Saraiva, 2003.

CONJUR. OAB-SP faz desagravo em favor de advogados ofendidos. 2013. OAB BA. Disponível em: http://www.oab-ba.org.br/noticia/oab-sp-faz-desagravo-em-favorde-advogados-ofendidos. Acesso em: 16.jan.2019.

DAVID, René. Le droit comparé enseignement de culture générale. Revue Internationale de Droit Comparé. Paris, a. 12, n. 4. out./dez. 1950.

MACHADO, Rubens Approbato. Comentários à nova lei de falência e recuperação de empresas, doutrinas e práticas. São Paulo: Quartier Latin, 2005.

PAES DE ALMEIDA, Amador. Curso de falência e concordata. 17 $7^{a}$ ed. ampl. e atual. São Paulo: Saraiva, 1999.

RODRIGUES, Silvio. Direito civil, volume 01 - parte geral. 34를 edição, 6ª tiragem. São Paulo: Saraiva, 2007.

SIMÃO FILHO, Adalberto. Direito empresarial II. (Coleção saberes do direito; Vol. 28). - São Paulo: Saraiva, 2012. 
VALOR. Pedidos de recuperação judicial batem recorde em 2016, nota Serasa. 2017. Disponível em: https://www.valor.com.br/brasil/4824392/pedidos-derecuperacao-judicial-batem-recorde-em-2016-nota-serasa. Acesso em: 19.jan.2018.

VALVERDE, Trajano de Miranda. Comentários à lei de falências. 4. ed. Rio de Janeiro: Forense, 1999a, v. 1 e v. 2. 